\title{
Amygdala and Emotion: The Bright Side of It
}

\author{
Mathias Weymar ${ }^{1 *}$ and Lars Schwabe ${ }^{2 *}$ \\ ${ }^{1}$ Department of Biological and Clinical Psychology, University of Greifswald, Greifswald, Germany, ${ }^{2}$ Department of Cognitive \\ Psychology, University of Hamburg, Hamburg, Germany
}

Keywords: emotion, amygdala, fMRI, affective neuroscience, arousal

\section{A commentary on}

The role of the amygdala in the perception of positive emotions: an "intensity detector" By Bonnet, L., Comte, A., Tatu, L., Millot, J.-L., Moulin, T., and Medeiros de Bustos, E. (2015). Front. Behav. Neurosci. 9:178. doi: 10.3389/fnbeh.2015.00178

It has long been known that the amygdala, a bilateral structure from the medial temporal lobe, is related to emotion, particularly in processing of aversive information (e.g., LeDoux, 1996). However, accumulating evidence suggests that amygdala activation is also involved in processing pleasant information, as observed, for instance, in studies using reward-learning (e.g., Adolphs, 2010; Janak and Tye, 2015), episodic memory encoding (e.g., Hamann et al., 1999; Dolcos et al., 2004), pleasant scene or face perception (e.g., Sabatinelli et al., 2011) or mental imagery of pleasant experiences (e.g., Costa et al., 2010). In a broader sense, the amygdala has been discussed as a key structure triggering the organisms' survival circuit that is organized into distinct motivational systems, the appetitive and defensive motivation system (Lang and Bradley, 2010). These systems engage processes that facilitate attention allocation and perceptual processing (Anderson and Phelps, 2001; Vuilleumier, 2005; Schwabe et al., 2011), associated with prioritized memory storage (McGaugh, 2015), and initiate metabolic changes (arousal) in order to mobilize the organism for appropriate coping actions, such as approach or avoidance (e.g., Lang and Bradley, 2013). Based on animal models (see for overview Davis and Whalen, 2001; Davis and Lang, 2003), these primary functions are served by bundles of nuclei within the amygdala, which receive input from various sources, such as cortex and thalamus (sensory) or hippocampus and in turn project to regions that mediate various cognitive functions (e.g., vigilance, attention, memory) as well as other processes (e.g., autonomic and somatic) and together facilitate such survival actions.

The activation of both motivating systems by pleasant or unpleasant external and internal events can also vary by intensity (arousal), which is described as the strength of motivational mobilization (Russell, 2003; Lang and Bradley, 2013). A majority of human neuroscience studies, however, found that the amygdala is activated by emotionally arousing stimuli, regardless of whether they are pleasant or unpleasant (Sabatinelli et al., 2011; but see Costafreda et al., 2008; Lindquist et al., 2016 for slight valence-differences), suggesting that the amygdala's predominant role may be the detection of emotionally arousing cues and subsequent activation of the organisms' motivational circuitry. A new study by Bonnet et al. (2015) provides additional evidence for such an "arousal" view. In this fMRI study, BOLD activity was measured while participants viewed pleasant visual scenes that varied in emotional arousal. This simple, but elegant, approach ensured that the outcome was not confounded with valence differences. Notably, in addition to neural activation, reactivity of the autonomic nervous system (skin conductance response) was simultaneously assessed in the scanner environment, and subjective ratings were obtained 1 month after scene encoding. The authors found that when pictures were rated high in arousal, stronger activation of the amygdala and hypothalamus was observed, as well as increased autonomic reactivity, in 
comparison to pictures receiving low arousal ratings. These results fit nicely with previous data showing covariations between sympathetic skin conductance responses and rated arousal levels of affective scenes, irrespective of their valence (e.g., Lang et al., 1993; Bradley et al., 2001). The findings of Bonnet and colleagues are also in line with animal data (summarized in e.g., Davis and Whalen, 2001; Lang and Davis, 2006) showing that projections from the amygdala (central nucleus) to the lateral hypothalamus prompt strong sympathetic activation, in terms of tachycardia, blood pressure elevation, pupil dilation and, likewise, increase in skin conductance. Although the amygdala is sensitive to arousing stimuli, "intensity detection," as suggested by Bonnet and colleagues, seems not to be the only role for this structure (e.g., Adolphs, 2010). Previous studies found that the amygdala is also responsive to novelty and prediction error (e.g., Hamann et al., 2002; Blackford et al., 2010; Roesch et al., 2010; Wendt et al., 2011). These findings rather suggest that the amygdala, in a broader view, is important to tag salient cues in our environment or to assign values to important cues. The functional significance might be to interrupt on-going mental activity and automatically direct attention toward this external signal, and initiate other processes to promote appropriate motivational actions.

Although the data by Bonnet et al. (2015) appear to suggest that there is a common brain system that represents both unpleasant and pleasant affect, this is still under debate (e.g., Lang and Bradley, 2010; Fernando et al., 2013; Janak and Tye, 2015; Lindquist et al., 2016). Some cell populations in the amygdala have been found to respond to both fear- and reward-related stimuli in rats (Shabel and Janak, 2009), which were also related to activation of the autonomic nervous

\section{REFERENCES}

Adolphs, R. (2010). What does the amygdala contribute to social cognition? Ann. N.Y. Acad. Sci. 1191, 42-61. doi: 10.1111/j.1749-6632.2010. 05445.X

Anderson, A. K., and Phelps, E. A. (2001). Lesions of the human amygdala impair enhanced perception of emotionally salient events. Nature 411, 305-309. doi: $10.1038 / 35077083$

Blackford, J. U., Buckholtz, J. W., Avery, S. N., and Zald, D. H. (2010). A unique role for the human amygdala in novelty detection. Neuroimage 50, 1188-1193. doi: 10.1016/j.neuroimage.2009.12.083

Bonnet, L., Comte, A., Tatu, L., Millot, J.-L., Moulin, T., and Medeiros de Bustos, E. (2015). The role of the amygdala in the perception of positive emotions: an "intensity detector." Front. Behav. Neurosci. 9:178. doi: 10.3389/fnbeh.2015.00178

Bradley, M. M., Codispoti, M., Cuthbert, B. N., and Lang, P. J. (2001). Emotion and motivation I: defensive and appetitive reactions in picture processing. Emotion 1, 276-298. doi: 10.1037/1528-3542.1.3.276

Costa, V. D., Lang, P. J., Sabatinelli, D., Versace, F., and Bradley, M. M. (2010). Emotional imagery: assessing pleasure and arousal in the brain's reward circuitry. Hum. Brain Mapp. 31, 1446-1457. doi: 10.1002/hbm. 20948

Costafreda, S. G., Brammer, M. J., David, A. S., and Fu, C. H. Y. (2008). Predictors of amygdala activation during the processing of emo-tional stimuli: a meta-analysis of 385 PET and fMRI studies. Brain Res. Rev. 58, 57-70. doi: 10.1016/j.brainresrev.2007.10.012

Davis, M., and Lang, P. J. (2003). "Emotion," in Handbook of Psychology, Vol. 3: Biological Psychology, eds M. Gallagher and R. J. Nelson (New York, NY: Wiley), 405-439. system (e.g., blood pressure), substantiating the view that the amygdala encodes saliency and triggers sympathetic nervous system activation. However, other cell ensembles in the amygdala encode unpleasant and pleasant value in a distinct fashion (e.g., Paton et al., 2006; Namburi et al., 2015). Especially, pleasant cues (e.g., Sabatinelli et al., 2007; Costa et al., 2010; Janak and Tye, 2015) have been shown to activate a neural circuit, including the amygdala, medial prefrontal cortex and the nucleus accumbens, that contributes more to reward-seeking behavior (e.g., Russo and Nestler, 2013), suggesting that some reactions in neural circuits are selectively prompted by appetitive cues. Future research needs to address how the amygdala interacts with these parallel and shared micro- and functional networks in the brain supporting salience and valence to affect specific motivated behavior (Janak and Tye, 2015; Lindquist et al., 2016). This could also help to better explain drug addiction (Kauer and Malenka, 2007), mood disorders (Russo and Nestler, 2013) and obsessivecompulsive disorders (Wood and Ahmari, 2015), which may be not only related to abnormalities in the adaptive function of the reward system, as assumed.

\section{AUTHOR CONTRIBUTIONS}

MW has drafted this commentary, LS provided critical revisions. Both authors approved the final version of the manuscript.

\section{ACKNOWLEDGMENTS}

The authors wish to thank Alfons O. Hamm for valuable suggestions on an earlier version of the manuscript.

Davis, M., and Whalen, P. J. (2001). The amygdala: vigilance and emotion. Mol. Psychiatry 6, 13-34. doi: 10.1038/sj.mp.4000812

Dolcos, F., LaBar, K. S., and Cabeza, R. (2004). Interaction between the amygdala and the medial temporal lobe memory system predicts better memory for emotional events. Neuron 42, 855-863. doi: 10.1016/S0896-6273(04)00289-2

Fernando, A. B. P., Murray, J. E., and Milton, A. L. (2013). The amygdala: securing pleasure and avoiding pain. Front. Behav. Neurosci. 7:190. doi: 10.3389/fnbeh.2013.00190

Hamann, S. B., Ely, T. D., Grafton, S. T., and Kilts, C. D. (1999). Amygdala activity related to enhanced memory for pleasant and aversive stimuli. Nat. Neurosci. 2, 289-293. doi: 10.1038/6404

Hamann, S. B., Ely, T. D., Hoffman, J. M., and Kilts, C. D. (2002). Ecstasy and agony: activation of the human amygdala in positive and negative emotion. Psychol. Sci. 13, 135-141. doi: 10.1111/1467-9280.00425

Janak, P. H., and Tye, K. M. (2015). From circuits to behaviour in the amygdala. Nature 517, 284-292. doi: 10.1038/nature14188

Kauer, J. A., and Malenka, R. C. (2007). Synaptic plasticity and addiction. Nat. Rev. Neurosci. 8, 844-858. doi: 10.1038/nrn2234

Lang, P. J., and Bradley, M. M. (2010). Emotion and the motivational brain. Biol. Psychol. 84, 437-450. doi: 10.1016/j.biopsycho.2009.10.007

Lang, P. J., and Bradley, M. M. (2013). Appetitive and defensive motivation: goal-directed or goal-determined? Emot. Rev. 5, 230-234. doi: $10.1177 / 1754073913477511$

Lang, P. J., and Davis, M. (2006). Emotion, motivation, and the brain: reflex foundations in animal and human research. Prog. Brain Res. 156, 3-29. doi: 10.1016/S0079-6123(06)56001-7

Lang, P. J., Greenwald, M. K., Bradley, M. M., and Hamm, A. O. (1993). Looking at pictures: affective, facial, visceral, and behavioral reactions. Psychophysiology 30, 261-273. doi: 10.1111/j.1469-8986.1993.tb03352.x 
LeDoux, J. E. (ed.). (1996). The Emotional Brain. New York, NY: Simon \& Schuster. Lindquist, K. A., Satpute, A. B., Wager, T. D., Weber, J., and Barrett, L. F. (2016). The brain basis of positive and negative affect: evidence from a metaanalysis of the human neuroimaging literature. Cereb. Cortex 26, 1910-1922. doi: 10.1093/cercor/bhv001

McGaugh, J. L. (2015). Consolidating memories. Annu. Rev. Psychol. 66, 1-24. doi: 10.1146/annurev-psych-010814-014954

Namburi, P., Beyeler, A., Yorozu, S., Calhoon, G. G., Halbert, S. A., Wichmann, R., et al., (2015). A circuit mechanism for differentiating positive and negative associations. Nature 520, 675-678. doi: 10.1038/nature14366

Paton, J. J., Belova, M. A., Morrison, S. E., and Salzman, C. D. (2006). The primate amygdala represents the positive and negative value of visual stimuli during learning. Nature 439, 865-870. doi: 10.1038/nature04490

Roesch, M. R., Calu, D. J., Esber, G. R., and Schoenbaum, G. (2010). Neural correlates of variations in event processing during learning in basolateral amygdala. J. Neurosci. 30, 2464-2471. doi: 10.1523/JNEUROSCI.5781-09.2010

Russell, J. A. (2003). Core affect and the psychological construction of emotion. Psychol. Rev. 110, 145-172. doi: 10.1037/0033-295X.110.1.145

Russo, S. J., and Nestler, E. J. (2013). The brain reward circuitry in mood disorders. Nat. Rev. Neurosci. 14, 609-625. doi: 10.1038/nrn3381

Sabatinelli, D., Bradley, M. M., Lang, P. J., Costa, V. D., and Versace, F. (2007). Pleasure rather than salience activates human nucleus accumbens and medial prefrontal cortex. J. Neurophysiol. 98, 1374-1379. doi: 10.1152/jn.00230.2007

Sabatinelli, D., Fortune, E. E., Li, Q., Siddiqui, A., Krafft, C., Oliver, W. T., et al. (2011). Emotional perception: meta analyses of face and natural scene processing. Neuroimage 54, 2524-2533. doi: 10.1016/j.neuroimage.2010. 10.011
Schwabe, L., Merz, C. J., Walter, B., Vaitl, D., Wolf, O. T., and Stark, R. (2011). Emotional modulation of the attentional blink: the neural structures involved in capturing and holding attention. Neuropsychologia 49, 416-425. doi: 10.1016/j.neuropsychologia.2010.12.037

Shabel, S. J., and Janak, P. H. (2009). Substantial similarity in amygdala neuronal activity during conditioned appetitive and aversive emotional arousal. Proc. Natl Acad. Sci. U.S.A 106, 15031-15036. doi: 10.1073/pnas.0905580106

Vuilleumier, P. (2005). How brains beware: neural mechanisms of emotional attention. Trends. Cogn. Sci. 12, 585-594. doi: 10.1016/j.tics.2005.10.011

Wendt, J., Weike, A. I., Lotze, M., and Hamm, A. O. (2011). The functional connectivity between amygdala and extrastriate visual cortex activity during emotional picture processing depends on stimulus novelty. Biol. Psychol. 86, 203-209. doi: 10.1016/j.biopsycho.2010.11.009

Wood, J., and Ahmari, S. E. (2015). A framework for understanding the emerging role of corticolimbic-ventral striatal networks in OCD-associated repetitive behaviors. Front. Syst. Neurosci. 9:171. doi: 10.3389/fnsys.2015.00171

Conflict of Interest Statement: The authors declare that the research was conducted in the absence of any commercial or financial relationships that could be construed as a potential conflict of interest.

Copyright $\odot 2016$ Weymar and Schwabe. This is an open-access article distributed under the terms of the Creative Commons Attribution License (CC BY). The use, distribution or reproduction in other forums is permitted, provided the original author(s) or licensor are credited and that the original publication in this journal is cited, in accordance with accepted academic practice. No use, distribution or reproduction is permitted which does not comply with these terms. 